\title{
Analysis of the Performance of a Solar Thermoelectric Generator for Variable Leg Geometry with Nanofluid Cooling
}

\author{
Cristian Francisco Ramos-Castañeda ${ }^{1}$, Miguel Angel Olivares-Robles ${ }^{2, *(D)}$ and Juan Vicente Méndez-Méndez ${ }^{3}$ \\ 1 Instituto Politecnico Nacional, Seccion de Estudios de Posgrado e Investigacion, Escuela Nacional de Ciencias \\ Biologicas, Ciudad de Mexico 11340, Mexico; cramosc1201@alumno.ipn.mx \\ 2 Instituto Politecnico Nacional, Seccion de Estudios de Posgrado e Investigacion, Escuela Superior de \\ Ingenieria Mecanica y Electrica Unidad Culhuacan, Coyoacan, Ciudad de Mexico 04430, Mexico \\ 3 Instituto Politecnico Nacional, Centro de Nanociencias y Micro y Nanotecnologías, \\ Ciudad de Mexico 07738, Mexico; jmendezm@ipn.mx \\ * Correspondence: olivares@ipn.mx; Tel.: +52-5554957287
}

Citation: Ramos-Castañeda, C.F.; Olivares-Robles, M.A.;

Méndez-Méndez, J.V. Analysis of the Performance of a Solar

Thermoelectric Generator for Variable Leg Geometry with Nanofluid Cooling. Processes 2021, 9, 1352. https://doi.org/10.3390/pr9081352

Academic Editor: Alfredo Iranzo

Received: 24 June 2021

Accepted: 29 July 2021

Published: 1 August 2021

Publisher's Note: MDPI stays neutral with regard to jurisdictional claims in published maps and institutional affiliations.

Copyright: (c) 2021 by the authors. Licensee MDPI, Basel, Switzerland. This article is an open access article distributed under the terms and conditions of the Creative Commons Attribution (CC BY) license (https:// creativecommons.org/licenses/by/ $4.0 /)$.

\begin{abstract}
In this study, the impact of nanofluid use in solar-thermoelectric generators (Solar-TEG) on thermal performance is investigated through analysis and simulation methodology. For conventional cooling analysis, we use air as a coolant and graphene nanoplatelet aqueous nanofluids (GNAN) for nanofluid cooling. We make a comparison between traditional and nanofluid cooling to find the best performance. GNAN at a dispersion of $0.025,0.05,0.075$, and $0.1-\mathrm{wt} \%$ are added to the cooling system. GNAN has been used in the technological development of energy conversion. It has been proposed as a material to achieve better efficiency in Solar-TEG. Five different geometries are developed to analyze the efficiency in a Solar-TEG to find the optimal design. The impact of the thermal concentration relationship, substrate area, and convective transfer coefficient on Solar-TEG performance is investigated. To simplify and speed up simulations, we use equivalent models based on FEM. We are considering the properties of temperature-dependent semiconductors. For thermoelement materials, we use lead-tellurium. Lead-tellurium is an excellent material for thermoelectric study and supports large temperature ranges (up to $750 \mathrm{~K}$ ). The thermal concentration relationship depends on the substrate area, which affects the efficiency of Solar-TEG. The maximum efficiency between the five geometry types is $5.53 \%$, with a substrate of $110 \times 100 \mathrm{~mm}^{2}$. The efficiency and output power using $0.1 \%$ wt GNAN as the refrigerant is enhanced by $14.74 \%$ and $26.39 \%$. GNAN cooling improves compared to conventional fluid cooling in a Solar-TEG. Different convection coefficients are used to verify this fact.
\end{abstract}

Keywords: solar-thermoelectric generator (Solar-TEG); thermal concentration ratio; convection coefficient; radiation heat; nanofluids

\section{Introduction}

Thermoelectric generation systems (TEG) have undergone important advances in recent years due to the development of semiconductor materials, and thermoelectric devices have even been incorporated into domestic accessories. Thermoelectric generation has attracted much more attention by decreasing primary energy reserve and taking advantage of wasted heat $[1,2]$.

A thermoelectric generator (TEG) is usually composed of two thermoelements connected in series, an n-type and a p-type. Thermoelements are connected by a metal (copper) and sealed by an aluminum ceramic material on the upper and lower surfaces [3]. Various studies on TEGs have studied an extensive field focused on applications, such as automotive, aerospace, industrial, and everyday life [4-6]. Normally if a temperature gradient is applied in a TEG system, there will be an electric field in the opposite direction associated with the thermoelectric system. This phenomenon is called the thermoelectric effect $[7,8]$. 
Thus, one of the essential factors determining the efficiency of thermoelectric generation is the temperature difference $(\Delta T)$ between the hot and cold sides of the thermocouple.

Several researchers have studied graphene for the improvement of its mechanical, thermal, and physical-chemical properties. It has high thermal conductivity, less erosion, and higher stability than other nanoparticles studied. The literature focuses on studying the stability and thermal properties of GNPS. Nanofluid characteristics are affected by heat and mass transfer, such as Reynolds number (Re), nanoparticle concentration, the synthesis method, surface tension and shape of the nanoparticles, the effect of magnetic force, and the size of the nanoparticles.

For example, Figueiredo, M. et al. [9] studied nanofluids up to 1\% wt in aerosols. Heat transfer improvement came about because the surface tension of the nanofluid declined and increased the wettability, which caused better transfer between the system and the film.

Sanches, M. et al. [10] studied the mathematical and physical correlation of the thermal properties of materials with their structure and how this affected thermal performance by applying silver and alumina nanofluids by spraying. They showed that increasing the concentration of nanofluids affected the thermal conductivity and viscosity of the nanofluid and decreased the heat transfer coefficients.

Sandhya et al. [11] observed how the GNPS improved thermal conductivity, the viscosity, and the heat transfer capacity of the fluid in which the nanoparticles were dispersed. Objects that GNANs can be applied to include car radiators, electronic refrigeration, and solar cells.

In recent studies [12-17], a numerical simulation model was analyzed to study the performance of thermal thermoelectric generators with solar concentration (Solar TEGs). Nuwayhid et al. [15] installed a TEG on the side of a wood stove. The way the TEG was cooled was by natural air convection. It was designed to be inexpensive and to provide optimal power.

For nanoparticles, the thermal conductivity is a critical factor. The structure of graphene is two-dimensional, and the shape is hexagonal. Therefore, its thermal, mechanical, and electrical properties are parameters of a lot of interest. The thermal conductivity of graphene is approximately $3000-5000 \mathrm{~W} / \mathrm{mK}$ [17]. Another study [18,19] developed a conversion technique for converting solar energy into electrical energy based on the thermal concentration and Seebeck effect.

The efficiency of a TEG, considering conduction heat, radiation heat, convection heat, and using an $\mathrm{Al}_{2} \mathrm{O}_{3}$ (Alumina) compound as a substrate for the solar collector, is numerically investigated considering two geometric models. The material lead-tellurium $(\mathrm{Pb}-\mathrm{Te})$ was used by Schmitz et al. [20] in a model of a system considering temperaturedependent properties.

Zhou, M. et al. [21] analyzed the electrical power of a TEG system at different mass flow rates for the refrigerant and different inlet temperatures. Nanofluids in traditional thermal energy systems have demonstrated better thermophysical properties, such as viscosity, thermal diffusivity, and thermal conductivity in comparison with base fluids. This study showed that the addition of copper oxide nanoparticles improved the heat transfer compared to the water in the Solar-TEG cooling system. Furthermore, the nanofluid efficiency was enhanced by $14 \%$ in comparison with pure water.

Huang et al. [22] found an optimal geometric structure for thermoelectric coolers through an inverse approach. To find the optimal geometry, they found the cooling rate on the cold side. They studied the optimization of the geometry of thermoelectric coolers using a simplified gradient method.

Bahiraei and Hangi [23] studied the water-based magnetic ferritic nanofluid Mn-Zn in a countercurrent twin-tube heat exchanger using a two-phase Euler-Lagrange method with a quadrupole magnetic field. The nano-liquid flowed down the wall of the tube as a coolant, and the hot water flowed down the ring. They studied the influence of some characteristics, such as particle size, concentration of NPS, magnetic field amplitude, and Reynolds number. 
Faizal et al. [24] estimate the feasibility of designing a small solar collector to produce the same outlet temperature as the one intended. They used a nanofluid as a working fluid. Efficiency, size reduction, cost, and embodied energy savings were calculated using numerical methods for different nanofluids. It was estimated that $8857 \mathrm{~kg}, 8618 \mathrm{~kg}$, $10,239 \mathrm{~kg}$, and $8625 \mathrm{~kg}$ of total weight could be saved for 1000 solar collector units for $\mathrm{TiO}_{2}$, $\mathrm{Al}_{2} \mathrm{O}_{3}, \mathrm{CuO}$, and $\mathrm{SiO}_{2}$ nanofluids, respectively.

Hajian et al. and Kooetal $[25,26]$ investigated the importance of the size of the nanoparticles and the percentage used in the solution. A discussion of the side effects and side effects of highly concentrated nanofluids was presented. Distilled water heat pipe treatment was more stable than the nanofluid. The thermal resistance of the heat pipe and the response time were respectively reduced by $30 \%$ and $20 \%$ compared to distilled water. The actual thermal conductivity depended strongly on both the temperature of the particles and the liquid and the properties of the material. This fact is due to the longer action interval of the potential between the particles.

Peyghambarzadeh et al. and Naraki et al. [27,28] studied the heat transfer coefficient with water-dispersed nanofluids for a car radiator. $\mathrm{Fe}_{2} \mathrm{O}_{3}$ and $\mathrm{CuO}$ were added at $0.15,0.4$, and $0.65 \%$ wt considering the best $\mathrm{pH}$ for better stability. The Reynolds number on the fluid side varied between 50-1000. The use of nanofluids improved the heat transfer by $9 \%$.

Vermahmoudi et al. [29] conducted experiments to study the heat transfer coefficient of $\mathrm{FeO}$ nanofluids dissolved in water for air-cooled heat exchangers. It turned out that increasing the flow rate, Reynolds number, and concentration improves the heat transfer coefficient. However, increasing the inlet temperature of the nanofluid adversely affects the heat transfer coefficient.

Cuce et al. [30] studied the impact of nanofluids in TECs on performance parameters and cooling power. They place a water-cooled block on the hot side, and a water-to-air exchanger was put in to cool the system. $\mathrm{Al} 2 \mathrm{O} 3, \mathrm{TiO} 2$ and $\mathrm{SiO} 2$ are used at $0.1,0.5$, and $0.1 \%$ wt. They conclude that the best efficiency was obtained with $\mathrm{Al}_{2} \mathrm{O}_{3}$ at $30{ }^{\circ} \mathrm{C}$ with $26 \%$ for no-load conditions.

Xing et al. [31] showed that graphene nanoplatelets could reduce nanofluid deposition and standardization. The simulation uses thermoelectric and liquid modules in an Ansys workbench environment. GNAN is used as a coolant on the TEG's cold side to achieve a better heat transfer. The results show that the heat, efficiency, output power, and voltage absorbed by the hot surfaces of the TEG system were increased by the liquid nano coolant.

Mohammadian and Zhang [32] studied the effect of alumina nanoparticles in water on the COP of a TEC. They concluded that COP could be improved by using nanofluids on the hot side with low Re.

Selimefendigil and Öztop [33] evaluated the efficiency of the TEG module located between two channels, carbon/water nanotubes flow with combined effects of particle inclusion, and flow pulsations, and with a Re $=250-1000$, mass fraction of 0.01 and $0.04 \%$ wt, Strouhal number $=0.01-0.1$, and amplitude $=0.25-0.95$. When nanoparticle mass fraction, Re, flow pulsation, and amplitude rose, the efficiency improved.

Wiriyasart et al. [34] experimentally analyzed the performance of a TEC model compacted to a heat sink with nanofluid, ferrofluid, and water. $\mathrm{TiO}_{2}$ and $\mathrm{Fe}_{3} \mathrm{O}_{4}$ were used at 0.005 and $0.015 \%$ wt. The results showed that $\mathrm{Fe} 3 \mathrm{O} 4$ showed a heat transfer $12.57 \%$ higher than water and $\mathrm{TiO}_{2}$.

The use of nanofluids as coolant reduces the temperature on the cold side of Solar-TEG and increases the temperature gradient. In addition, nanofluids as refrigerants in Solar-TEG configurations improve TEG operating conditions better than water or air.

Using different geometries and how it influences the performance of the Solar-TEG, $\mathrm{PbTe}$ as a semiconductor material, and nanofluids as a refrigerant to improve performance, and including solar concentration makes this work a complete study.

In this study, the materials and methodology used for the simulation, the governing equations, the TEG schemes with and without a cooling system, and the different equivalent geometries proposed are presented in Section 2. In Section 3, the results for the efficiency, 
output power, and current as a function of the concentration ratio are presented. The heat, efficiency, and output power as a function of the Re with various concentrations of graphene nanoplatelets are obtained. The geometry of the TEG and the use of nanofluids is mentioned. Our results are obtained considering the influence of the thermal concentration ratio, nanofluids cooling, and convection heat on each model's efficiency and power output. We determine the spatial distribution of temperatures and the efficiency as a function of the thermal concentration ratio at different heat values of convection. Considering the convection coefficient and the solar concentration ratio, which is a relationship between the area of the substrate and the area of the thermocouple, we obtain the optimal geometric model for maximum performance in the TEG. The efficiency of the thermoelectric models is presented, along with the output power for different cases (rectangular and trapezoidal), and, finally, in Section 4, conclusions are presented.

\section{Materials and Methods}

The purpose of having five different geometries is to have points of comparison; because the surface area in all the geometries is different, the solar concentration will be different in all. This will cause changes in the analysis and results, which will be reflected in the cooling, efficiency, and power output.

\subsection{Solar Concentration}

In this study, simulations were done in an ANSYS workbench. For the analysis of a thermoelectric system, the input parameters for the simulation were defined: coordinate system and thermoelectric properties.

The analysis includes two thermoelements, a p-type and an n-type, composed of lead-tellurium. Copper electrodes are also included to make the connection in the transfer of electrons between the thermoelements. Finally, a substrate called a solar collector is placed where solar radiation is transferred. Generally, the substrate is bigger than the cross-sectional area of the Solar-TEG. This model is shown in Figure 1.

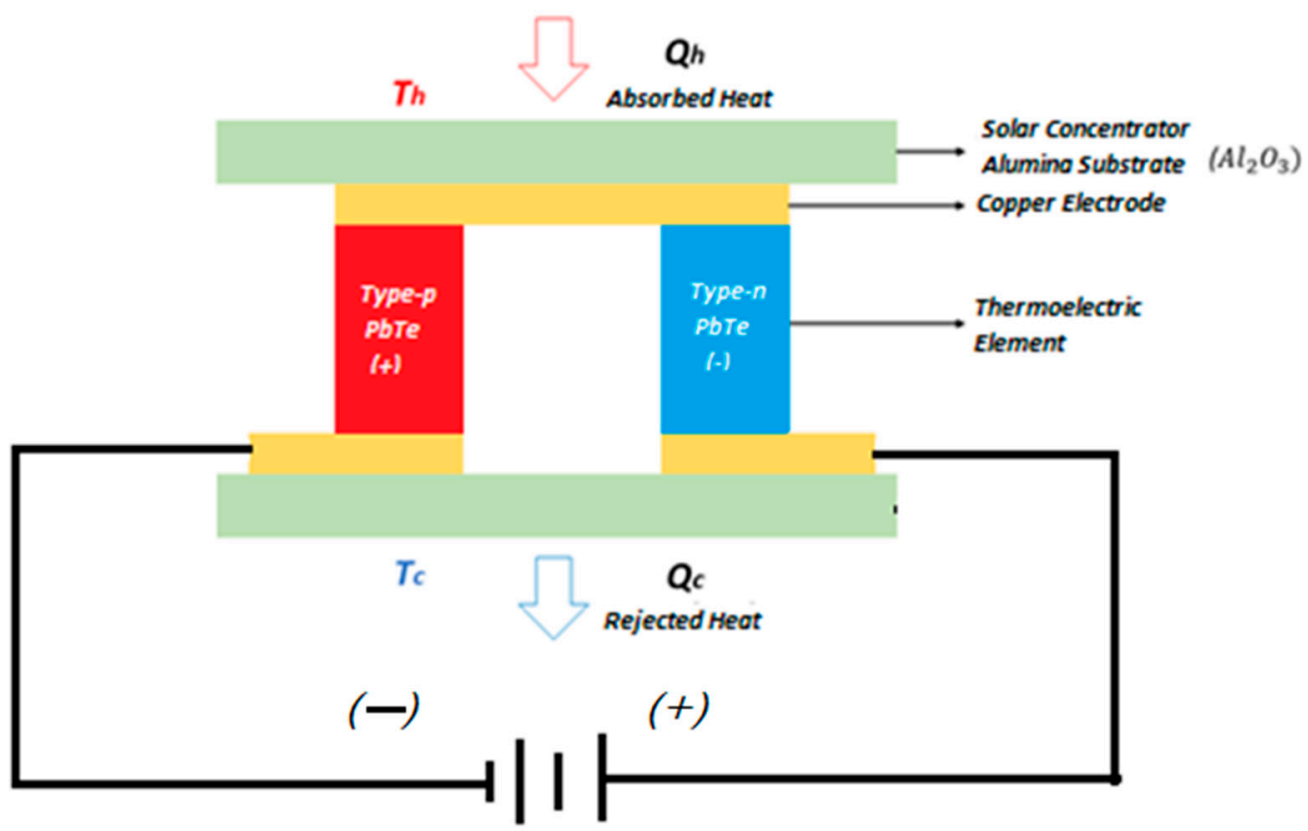

Figure 1. The geometry of a thermoelectric generator with an aluminum substrate $\left(\mathrm{Al}_{2} \mathrm{O}_{3}\right)$.

Before performing the simulations, the following conditions for the system are considered:

- The Solar-TEG is in a stationary state; its characteristics do not change over time. 
- $\quad \mathrm{N}$-type and p-type semiconductor configurations are the same. PbTe is the same material; both semiconductors and thermoelements are symmetrical with each other.

- The thermoelements are thermally connected in parallel and electrically in series.

- Semiconductor properties are temperature-dependent, but copper and the absorption substrate are constant.

- Radiation heat is only analyzed on the hot side of the Solar-TEG.

- The heat dissipator (sink) is not included in the simulation; its behavior by boundary conditions is described [8].

The thermoelectric materials behavior is defined by the following equations governing the system and relating the thermal and electric fields.

$$
\begin{aligned}
& \nabla \cdot(\alpha T \vec{J})-\nabla \cdot(k \nabla T)=\vec{J} \cdot \vec{E} \\
& \nabla \cdot\left(\frac{1}{\rho_{e}} \vec{E}\right)-\nabla \cdot\left(\frac{\alpha}{\rho_{e}} \nabla T\right)=0
\end{aligned}
$$

where $\alpha$ is the Seebeck coefficient; $T$ is the temperature; $\vec{E}$ is the electric field; $\vec{J}$ is the vector current density. $\rho_{e}$ and $k$ are the resistivity and the thermal conductivity, respectively, of the thermoelement.

We use the Stefan-Boltzmann equation to determine the radiation heat emitted by the solar collector into the environment.

$$
Q_{r d}=\varepsilon \sigma_{S B} A_{c} F\left(T_{H}^{4}-T_{\infty}^{4}\right)
$$

where $\varepsilon$ is the emissivity; $\sigma_{S B}$ is the Stephan-Boltzmann constant $\left(5.67 \times 10^{-8} \mathrm{~W} / \mathrm{m}^{2} \mathrm{~K}^{4}\right)$; $A_{c}$ is the cross-sectional area of the solar collector; $F$ is the area factor, a ratio between the actual area of the substrate and equivalent substrate area; $T_{H}$ is the temperature of the hot side of the system, and $T_{\infty}$ is room temperature.

The thermal concentration ratio is a relation between the substrate area and the area of the thermocouple; varying the size of the substrate will change the thermal concentration ratio.

$$
C_{\text {th }}=\frac{A_{\text {substrate }}}{2 *\left(A_{\text {thermoelement }}\right)}
$$

Based on this fact, we define four thermal concentration ratios for each thermocouple of the three proposed geometries, as shown in Table 1. Then, we compare the output power generated for each case and the efficiency with this concentration ratio, using the simulation results.

Table 1. Equivalent geometries dimensions.

\begin{tabular}{cc}
\hline Equivalent Geometry & Dimensions \\
\hline Model A & $1 \mathrm{~mm} \times 1 \mathrm{~mm} \times 1.6 \mathrm{~mm}$ \\
Model B & $1.4 \mathrm{~mm} \times 1.4 \mathrm{~mm} \times 1.6 \mathrm{~mm}$ \\
Model C & $2.8 \mathrm{~mm} \times 2.8 \mathrm{~mm} \times 3.5 \mathrm{~mm}$ \\
\hline
\end{tabular}

\section{Convection Coefficient}

It is assumed that the convection coefficient $h_{L}$ is uniform through the cold-side surface. In the case of the equivalent model, we use the area Factor $F$.

\subsection{Geometric Models}

Figure 2 shows the real model of the TEG with an aluminum substrate $(25 \mathrm{~mm} \times 25$ $\mathrm{mm})$ as a solar concentrator used in the simulation. 


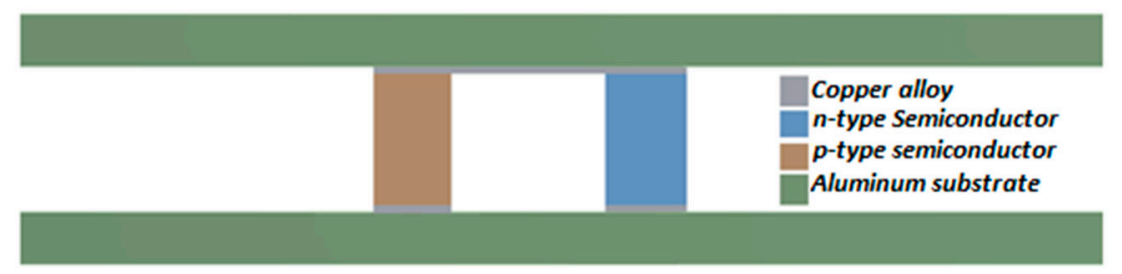

Figure 2. The real model of the TEG with solar concentrator showing the thermocouple.

Table 1 shows the dimensions of the three different geometries for the system, using the equivalent model proposed by Chen W. et al. [8]. Figure 3 shows equivalent geometries $\mathrm{A}, \mathrm{B}$, and $\mathrm{C}$ of the real designed models, wherein the surface area changes for all cases.

a)

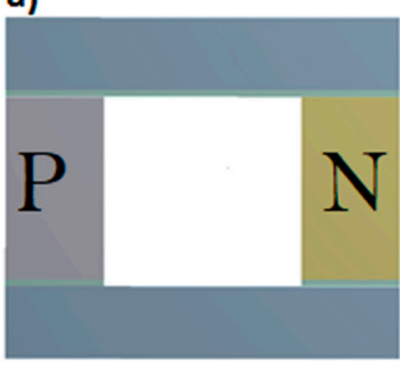

b)

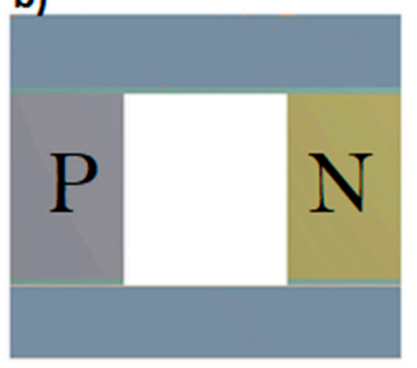

c)

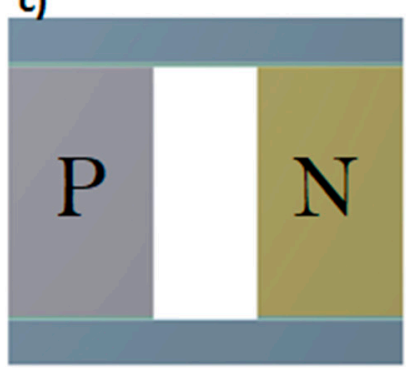

Figure 3. (a) Equivalent model of geometry A, (b) equivalent model of geometry B, (c) equivalent model of geometry $\mathrm{C}$.

Trapezoidal geometries are also considered to perform the same analysis with the same thermoelectric properties. The diagram of the TEG is shown in Figure 4, which consists of thermoelectric legs of p-type and n-type of trapezoidal shape interspersed between the heat sink and heat source, with a variable surface area. The geometric dimensions, such as the length, thickness, and cross-sectional area, of the p-type and n-type thermoelements are the same. Therefore, the temperature distribution in the p-type and n-type thermoelectric branches will be equal.
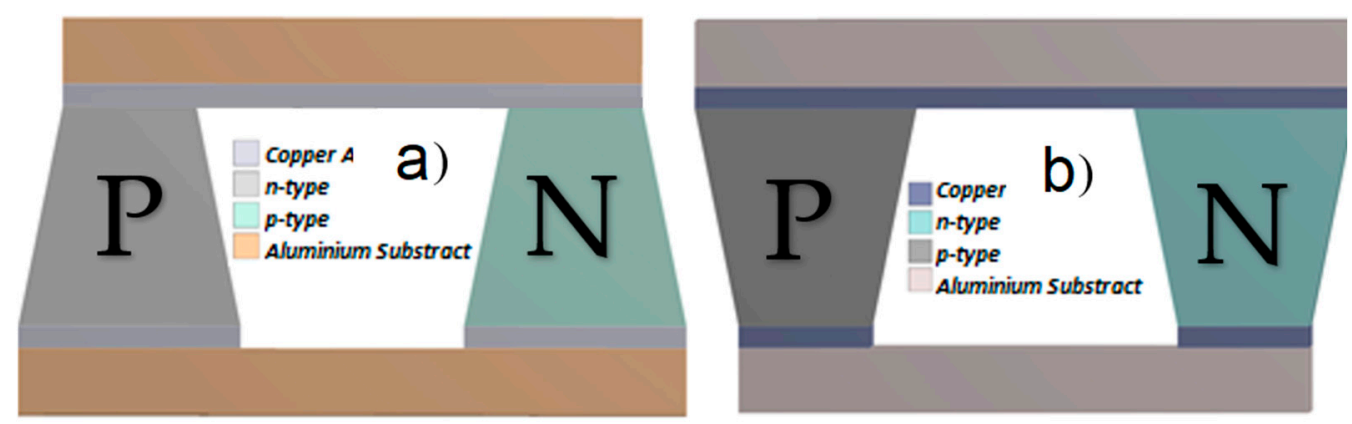

Figure 4. (a) Trapezoidal Geometric Model A: proposed TEG with dimensions on the hot side of $6 \mathrm{~mm} \times 6 \mathrm{~mm}$ and on the cold side $10 \mathrm{~mm} \times 10 \mathrm{~mm}$, with a separation of $10 \mathrm{~mm}$. (b) Trapezoidal Geometric Model B: inverse of Trapezoidal Geometric Model A [16].

\subsection{Nanofluid Cooling}

The specific surface area of graphene nanoplatelets is $750 \mathrm{~m}^{2} / \mathrm{g}$, and concentrations are $0.025 \%, 0.05 \%, 0.075 \%$, and $0.1 \%$ wt [29].

The density of the nanofluid can be calculated with:

$$
\rho=(1-\phi) \rho_{w}+\phi \rho_{g}
$$


where $\phi$ is the concentration of GNPS. Specific heat capacity Cp of the nanofluid can be defined as:

$$
C p=\frac{\phi \rho_{g} C p_{g}+(1-\phi) \rho_{w} C p_{w}}{\phi \rho_{g}+(1-\phi) \rho_{w}}
$$

The numerical values of graphene nanoplatelets and distilled water parameters, such as the density of water $\rho_{w}$, the specific heat capacity of distilled water $C p_{w}$, the density of graphene nanoplatelets $\rho_{g}$, the graphene nanoplatelets' specific heat capacity $C p_{g}$, are shown in Table 2. The nanofluid parameters, including the thermal conductivity of the nanofluid $\lambda$ and the kinematic viscosity of the nanofluid $v$, are listed in Table 3. The structure of graphene is two-dimensional, composed of a hexagonal structure of carbon atoms. Graphene is a $120^{\circ} \mathrm{sp} 2$ hybridized carbon atom attached to three other carbon atoms. These are on the same plane.

Table 2. Physical parameters of distilled water and graphene nanoplatelets [29].

\begin{tabular}{cccc}
\hline$\rho_{w} / \mathrm{kg} \cdot \mathrm{m}^{-3}$ & $\rho_{g} / \mathrm{kg} \cdot \mathrm{m}^{-3}$ & $C p_{w} / \mathrm{J} \cdot \mathrm{kg}^{-1} \cdot \mathrm{K}^{-1}$ & $C p_{g} / \mathrm{J} \cdot \mathrm{kg}^{-1} \cdot \mathrm{K}^{-1}$ \\
\hline 997 & 2250 & 4181.7 & 1400 \\
\hline
\end{tabular}

Table 3. Nanofluid Physical Parameters [29].

\begin{tabular}{|c|c|c|c|c|c|c|}
\hline & $\lambda / \mathrm{W} \cdot \mathrm{m}^{-1} \cdot \mathrm{K}^{-1}$ & $v / 10^{-7} \mathrm{~m}^{2} \cdot \mathrm{s}^{-1}$ & $\rho / \mathrm{kg} \cdot \mathrm{m}^{-3}$ & $\mathrm{Cp} / \mathrm{J} \cdot \mathrm{kg}^{-1} \cdot \mathrm{K}^{-1}$ & Shape & $\begin{array}{c}\text { Surface } \\
\text { Tension } / \mathrm{mN} \cdot \mathrm{m}^{-1}\end{array}$ \\
\hline $\begin{array}{c}\text { Distilled water } \\
0.025-\mathrm{wt} \%\end{array}$ & 0.6 & 7.47797 & 997 & 4181.7 & - & 72.13 \\
\hline $\begin{array}{c}\text { nanofluids } \\
\text { dispersed in } \\
\text { graphene } \\
0.05-w \mathrm{t} \%\end{array}$ & 0.68 & 8.94441 & 1028.575 & 3952.767 & Hexagonal & 70.94 \\
\hline $\begin{array}{c}\text { nanofluids } \\
\text { dispersed in } \\
\text { graphene } \\
\text { 0.075-wt } \%\end{array}$ & 0.705 & 9.24397 & 1060.15 & 3737.470 & Hexagonal & 69.77 \\
\hline $\begin{array}{l}\text { nanofluids } \\
\text { dispersed in } \\
\text { graphene }\end{array}$ & 0.73 & 9.52621 & 1091.725 & 3534.628 & Hexagonal & 68.03 \\
\hline $\begin{array}{c}0.1-\mathrm{wt} \% \text { nanofluids } \\
\text { dispersed in } \\
\text { graphene }\end{array}$ & 0.752 & 9.97062 & 1123.3 & 3343.188 & Hexagonal & 66.3 \\
\hline
\end{tabular}

Suppose the refrigerant is detected in the laminar flow development stages, and the influence of different physical properties is negligible. In this case, the Nusselt number with a distance of $0.052 \mathrm{~m}$ can be described by the Zader-Tate equation.

$$
N u=1.86\left(\frac{\operatorname{RePr}}{l / d e}\right)^{1 / 3}
$$

where $\operatorname{Pr}=\rho v C p / \lambda$ is the Prandtl number; $R e=u d e / v$ is the Reynolds number, and $d e=4 A_{f} / B$ is the equivalent diameter. In those equations, $v$ is the kinematic viscosity; $u$ is the flow; $A_{f}$ is the viscosity; $\lambda$ is the thermal conductivity; $B$ is the wet perimeter, and $h_{L}=\lambda N u / l$ is the heat transfer coefficient.

\subsection{TEG and Nanofluids System}

The fluid alternates between the heat exchanger, the cabin pump and the condenser. As shown in Figure 5, the liquid is heated through the radiator, liquid cabinet, and pump, cooled by the condenser, and finally returned to the radiator. 

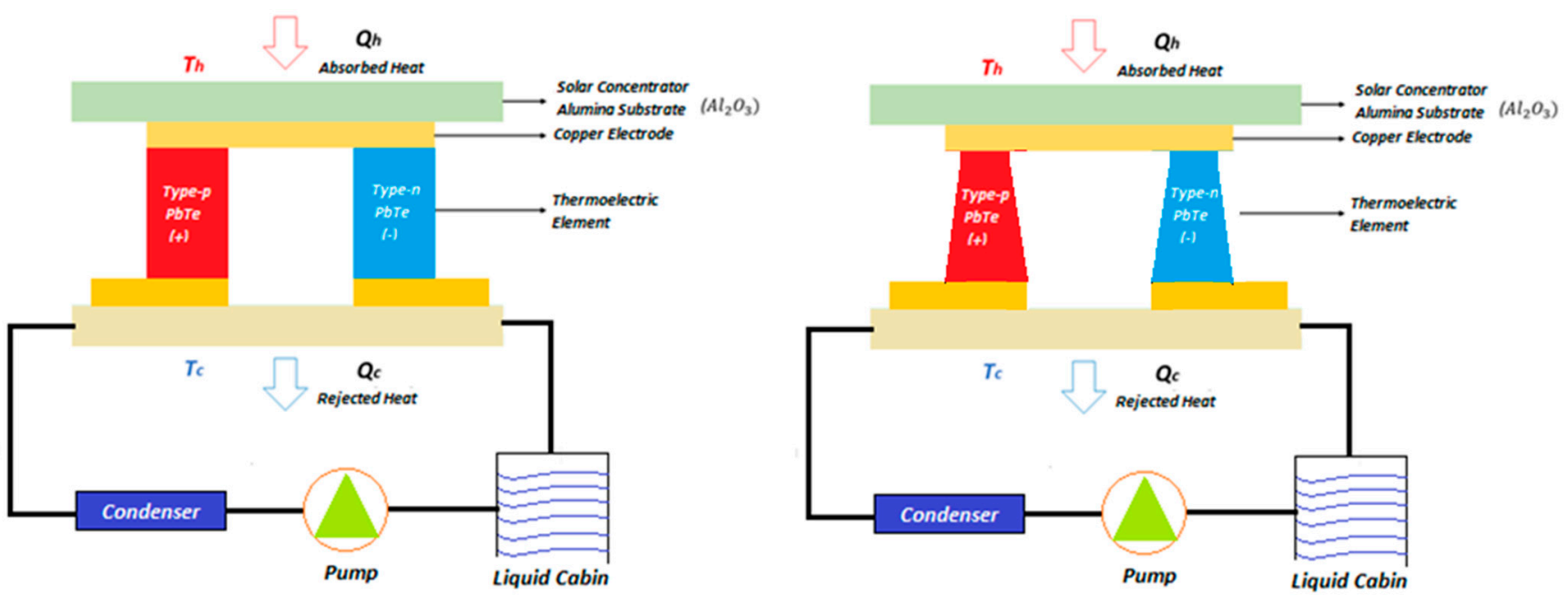

Figure 5. Schematic diagram of the solar TEG and its cooling structure for rectangular models and trapezoidal models.

The pump is only used to make the nanofluid flow through the system; it is not considered a specific pump, and we consider an ideal efficiency for distilled water.

In this study, water-based nanofluids of graphene nanoplates were used as refrigerants for the cold side to increase convertibility. The specific heat capacity of refrigerants is high, and it causes a negligible change between them. The refrigerant temperature is $303 \mathrm{~K}$.

Heat loss from semiconductors and thermal resistances in cooling tube and ceramic plates is ignored

\section{Results and Discussion}

Power output and overall efficiency increase as $C_{\text {th }}$ increases under all cooling conditions. In this work, the results are obtained considering that $\mathrm{PbTe}$ is temperature dependent, which operates at a $\Delta \mathrm{T}=350 \mathrm{~K}$. The temperature distribution in the n-type and p-type elements, the efficiency, and the electric current generated is obtained considering: (a) a substrate that works as a solar concentrator, (b) the convection coefficient, and (c) different geometries of the semiconductor elements.

Lead-tellurium operates in a higher temperature range than bismuth-tellurium. Since the properties are temperature-dependent, the radiation heat is greater, and the power output and efficiency are estimated to operate under optimal conditions; the efficiency reaches $6 \%$ or more.

\subsection{Conventional Cooling}

Simulations and analyses were carried out for rectangular and trapezoidal models with conventional cooling. Air is used as the cooling fluid, whose properties are shown in Table 4 based on Chen W. et al. [8].

Table 4. Properties of the coolant.

\begin{tabular}{cc}
\hline Coolant & Property \\
& $\rho_{a}=1.1707 \mathrm{~kg} \mathrm{~m}^{-3}$ \\
Air & $\mu_{a}=183.6 \times 10^{-7} \mathrm{~N} \mathrm{~s} \mathrm{~m}^{-2}$ \\
$C_{p, a}=1007 \mathrm{~J} \mathrm{~kg}^{-1} \mathrm{~K}^{-1}$
\end{tabular}

\subsubsection{Rectangular Models}

The ambient temperature is taken as the cold side temperature $(298 \mathrm{~K})$ up to $648.15 \mathrm{~K}$ for the hot side. Figure 6 shows the temperature distribution for each equivalent geometry. 


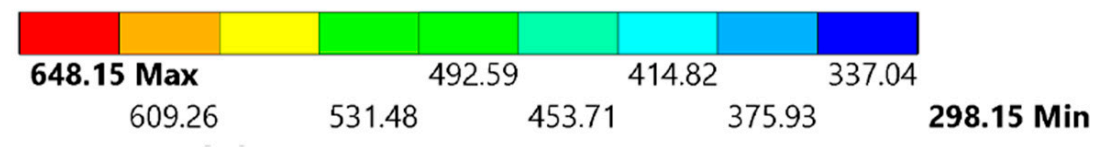

a)

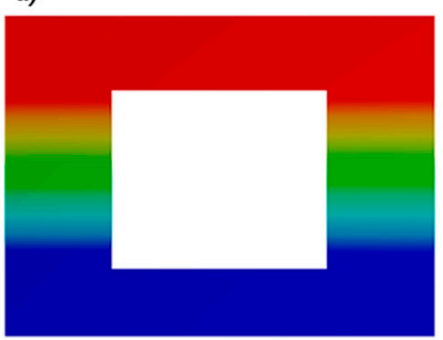

b)

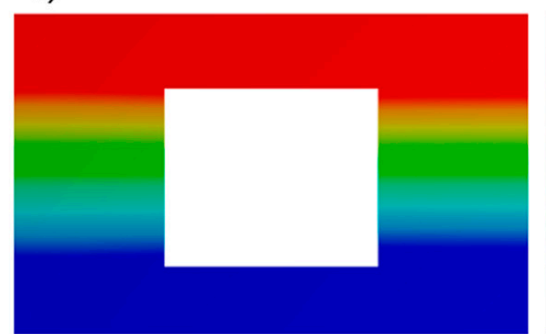

c)

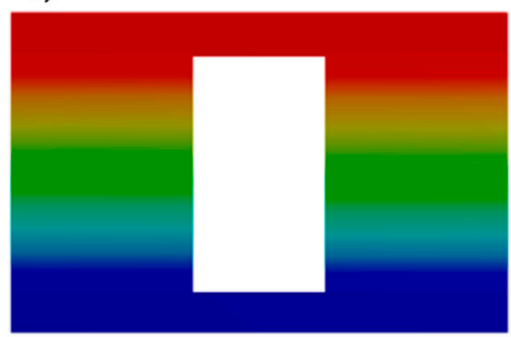

Figure 6. Temperature distribution of rectangular models: (a) Model A, (b) Model B, (c) Model C.

Using Equation (3), the radiation heat that the TEG radiates to the environment is a function that depends on the area of the solar concentrator, so the greater the area, the greater the radiation heat increase. With Figure 6, we can assume that the maximum radiated heat will be that of model $C$; the geometry with the largest area will have a large radiative dissipation. The maximum radiation heat for models $\mathrm{A}, \mathrm{B}$, and $\mathrm{C}$ is $0.00306 \mathrm{~W}$, $0.00514 \mathrm{~W}$, and $0.01627 \mathrm{~W}$.

The currents generated for each geometry do not vary much from the real ones; their respective equivalent geometries are shown in Figure 7. Knowing that the thermal concentration ratio is a relation between the substrate area and the area of the thermocouple, according to Equation (4), Cth is an adimensional parameter. The maximum output power for equivalent models $\mathrm{A}, \mathrm{B}$, and $\mathrm{C}$ is $0.5916 \mathrm{~W}, 0.5671 \mathrm{~W}$, and $0.3983 \mathrm{~W}$, respectively. The maximum output power for models $\mathrm{A}, \mathrm{B}$, and $\mathrm{C}$ is $0.5812 \mathrm{~W}, 0.5474 \mathrm{~W}$, and $0.3781 \mathrm{~W}$, respectively. The output power for commercial models and equivalent models is almost the same; the difference is minimal. An increase in $\mathrm{C}_{\mathrm{th}}$ increases $\mathrm{P}_{\text {out }}$, disregarding the type of geometry.

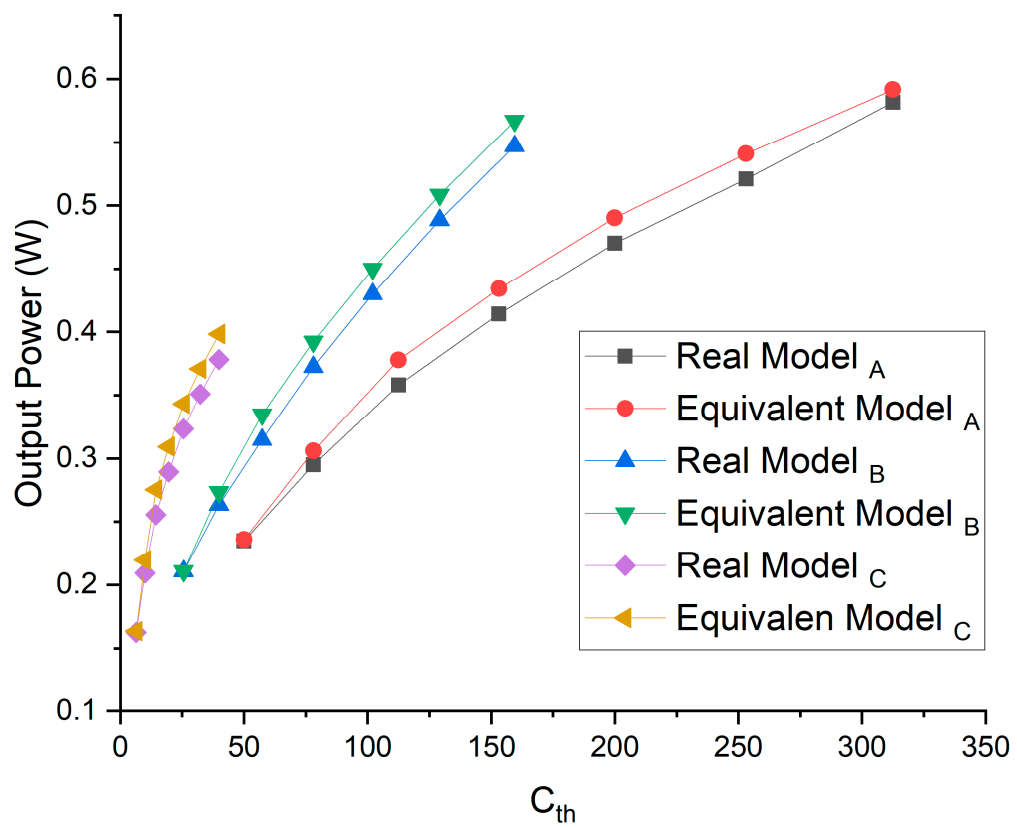

Figure 7. Output power vs. $C_{\text {th }}$ (adimensional unit) for each geometry in its real and equivalent model.

In Table 5 and Figure 8, the thermal concentration ratio increases as the substrate size increases. Therefore, equivalent models overestimate Solar-TEG performance. However, 
due to the low heat concentration coefficient, the model results are close to the actual model results. The difference between these two models is evident when the concentrated heat is reasonably significant, even under the same boundary conditions.

Table 5. Substrate areas and thermal concentration ratio calculated for rectangular models.

\begin{tabular}{ccccc}
\hline \multirow{2}{*}{ No. Substrate } & Area $\left.\mathbf{( m m}^{\mathbf{2}}\right)$ & \multicolumn{3}{c}{ Thermal Concentration Ratio } \\
\cline { 3 - 5 } & & Geometry A & Geometry B & Geometry C \\
\hline 1 & $40 \times 40$ & 50 & 25.51 & 6.38 \\
2 & $80 \times 80$ & 200 & 102.04 & 25.51 \\
3 & $100 \times 100$ & 312.5 & 159.44 & 39.86 \\
4 & $110 \times 110$ & 378.13 & 192.12 & 48.23 \\
\hline
\end{tabular}

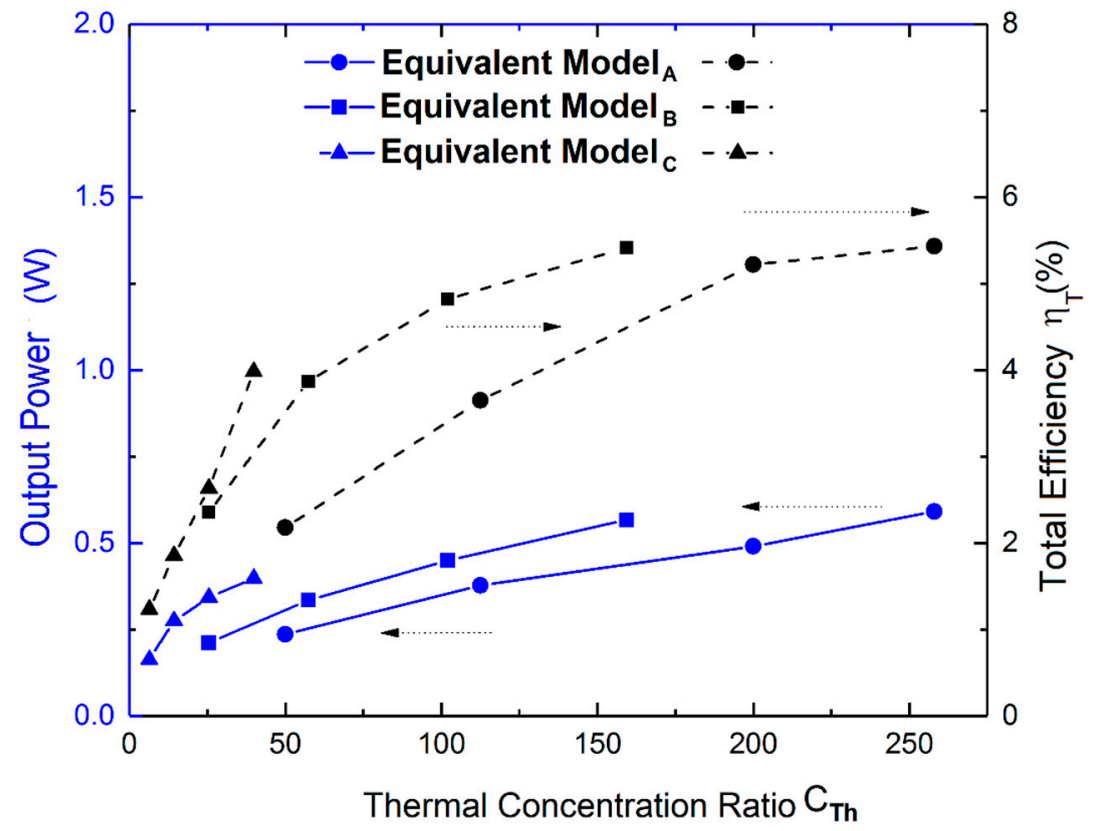

Figure 8. Efficiency and output power of the three equivalent models with a different thermal concentration ratio (adimensional unit).

In Figure 8, the power output and efficiency are calculated using the following equation:

$$
\eta_{T}=\eta_{T E G} \cdot \eta_{o p t} \cdot \eta_{\alpha}
$$

where $\eta_{o p t}$ is the optical efficiency, which is $85 \%$; $\eta_{\alpha}$ is the absorption efficiency (0.93), and $\eta_{T E G}=P_{\text {out }} / Q_{\text {in }}$.

Gradually increasing the heat concentration factor will gradually increase the output, regardless of the shape. Therefore, increasing the thermal concentration factor also improves $\eta_{T}$ of the Solar-TEG in monotone rectangular models B and C. At the same time, Geometry A has an optimal heat concentration ratio or area $\left(80 \times 80 \mathrm{~mm}^{2}\right)$ with a TEG of $5.3 \%$. This is due to the low ZT value of thermoelectric materials when the temperature is high. As a result, the maximum efficiencies of models B and C correspond to $5.65 \%$ and $3.98 \%$, respectively.

Table 5 shown the effect of the substrate area or Cth on the TEG performance of eight different board regions and the relationship between the heat concentrations of each of the four board regions of the three geometries. A surface area of $40 \times 40 \mathrm{~mm}^{2}$ is the most common size of thermoelectric modules on the market and is considered the smallest, and $110 \times 110 \mathrm{~mm}^{2}$ is the largest. 
Compared with Chen W. et al. [8], who they used bismuth-tellurium as a semiconductor material, the maximum efficiency is $4.15 \%$. Therefore, by using lead-tellurium as the material, we obtained better performance.

\subsubsection{Trapezoidal Models}

The trapezoidal area creates an asymmetric thermal resistance; Joule heat is directed to the smaller section.

Figure 9 shows the temperature distribution with a convection coefficient of $2000 \mathrm{~W} / \mathrm{m}^{2} \mathrm{~K}$ for trapezoidal models. Lamba et al. [15] show that, when the convection coefficient is not considered in the calculations, the temperature distribution is uniform. Our results show the impact of the convection coefficient and the geometry of the elements in the temperature distribution. With the effect of convection heat, the heat that is entering the TEG becomes more profitable. When the convection coefficient is neglected, the distribution is linear, as shown in Figure 6. However, when the convection coefficient is applied between the Solar-TEG legs, the distribution shown in Figure 10 is an uneven distribution over thermoelements.

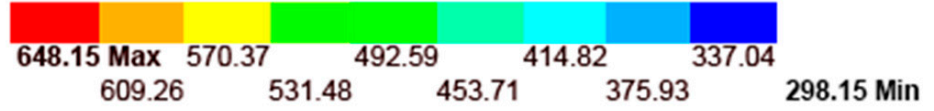

a) Trapezoidal Model $A$

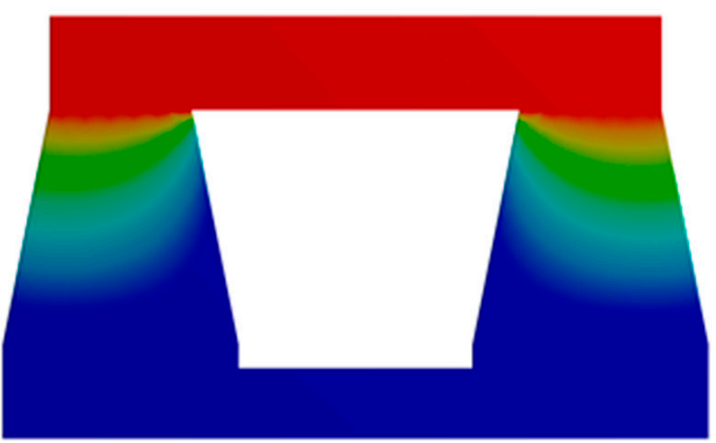

b) Trapezoidal Model $B$

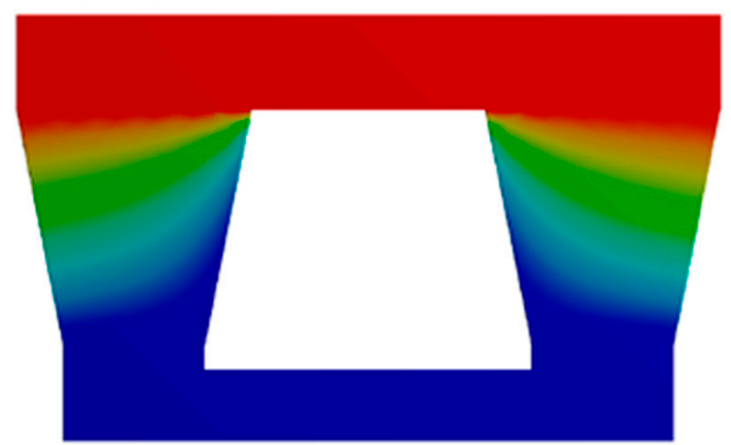

Figure 9. Temperature distribution with convection coefficient of $2000 \mathrm{~W} / \mathrm{m}^{2} \mathrm{~K}$ for: (a) Trapeziodal Model A and (b) Trapezoidal Model B.

According to Equation (6), we define eight thermal concentration ratios for each thermocouple of the two models, as shown in Table 6. With this concentration ratio, we compare the efficiencies generated for each case using the simulation results.

Table 6. Substrate areas and thermal concentration ratio calculated for trapezoidal models.

\begin{tabular}{cccc}
\hline \multirow{2}{*}{ No. Substrate } & Area $\left.\mathbf{( m m}^{\mathbf{2}}\right)$ & \multicolumn{2}{c}{ Thermal Concentration Ratio } \\
\cline { 3 - 4 } & $40 \times 20$ & Trapezoidal Model A & Trapezoidal Model B \\
\hline 1 & $50 \times 30$ & 11.11 & 4 \\
2 & $60 \times 40$ & 20.833 & 7.5 \\
3 & $70 \times 50$ & 33.333 & 12 \\
4 & $80 \times 60$ & 48.611 & 17.5 \\
5 & $90 \times 70$ & 66.666 & 24 \\
6 & $100 \times 80$ & 87.5 & 31.5 \\
7 & $110 \times 90$ & 111.111 & 40 \\
8 & & 137.5 & 49.5 \\
\hline
\end{tabular}




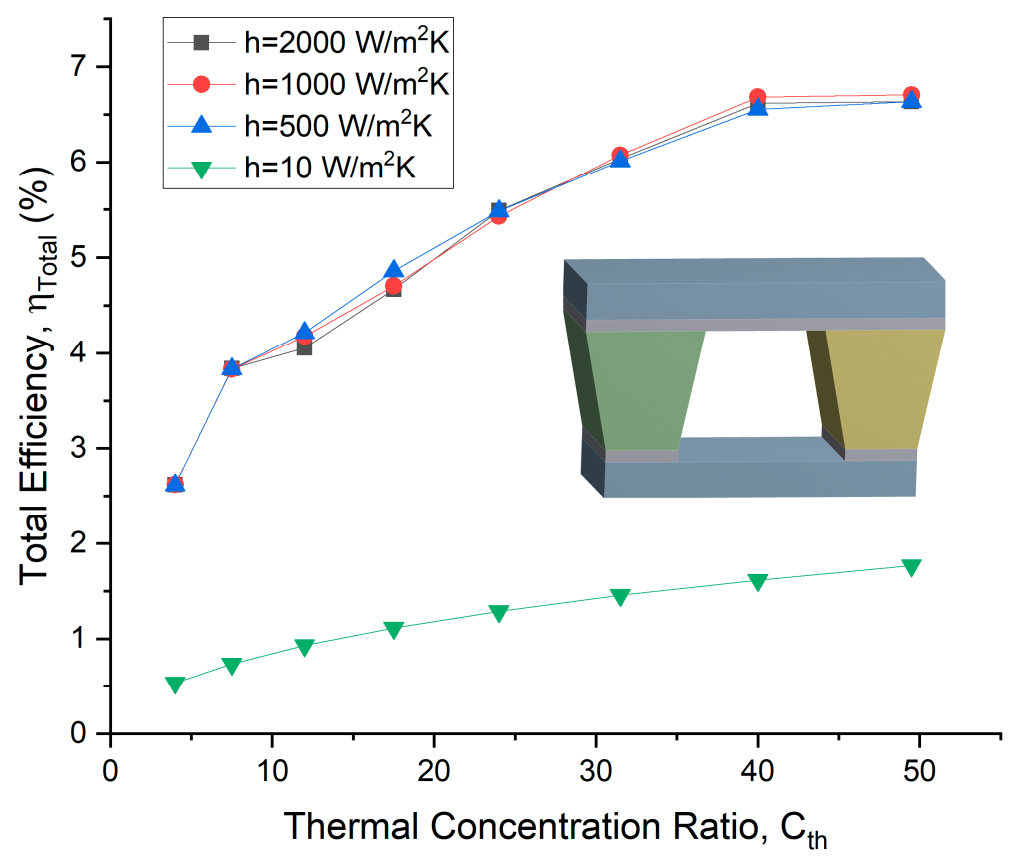

Figure 10. Efficiency vs. thermal concentration ratio (adimensional unit) for trapezoidal model B with different convection coefficients.

This case is considered when the convection coefficient is zero, but radiation and conduction are included. Due to Joule, heating is redirected towards the smallest crosssection, with the temperature distribution shown in Figure 10. Although trapezoidal model $\mathrm{B}$ has lower thermal concentration ratios, it can be seen that trapezoidal model $\mathrm{B}$ is more efficient than trapezoidal model A. The maximum efficiency of trapezoidal models A and $\mathrm{B}$ is $6.52 \%$ and $7.03 \%$, respectively.

Figure 10 shows efficiency as a function of the thermal concentration coefficient for different values of the convective coefficient for trapezoidal model B for the case when four different convective heat transfer coefficients are included for comparison. This geometric model's thermal concentration ratio values are smaller due to the contact area relationship between the substrate and the semiconductor elements, shown in Equation (6). If the thermal concentration coefficient increases, the overall efficiency increases for cooling conditions. When very high convective coefficient values are considered $(\mathrm{h}=500,1000 \mathrm{y}$ $2000 \mathrm{~W} / \mathrm{m}^{2} \mathrm{~K}$ ), the difference obtained is almost imperceptible. For very low values of convection coefficients $\left(\mathrm{h}=10 \mathrm{~W} / \mathrm{m}^{2} \mathrm{~K}\right)$, the efficiency is considerably reduced.

\subsection{Nanofluid Cooling}

The nanofluid passes through the sink of the cold side of the Solar-TEG. The heat $\mathrm{Q}_{\mathrm{h}}$ is radiated to the heat sink on the cold side of the TEG. The area of the heatsink is assumed to be equal to the substrate area of the thermoelectric module; the specified panel area determines the width and length of the heatsink. Thus, the heat dissipator temperature and the cold side temperature are the same.

\subsubsection{Rectangular Models}

Figure 11 shows three-dimensional electric potential at $\operatorname{Re}=1675$. The use of nanofluids causes better heat transfer and electric potential differences in the Solar-TEG. The electrical output potential is approximately $0.93 \mathrm{~V}$ with water with $0.1 \%$ graphene nanoplatelets dispersed as a coolant. The minimum edge length of the mesh is $1 \times 10^{-3} \mathrm{~m}$, and it consists of 19,962 nodes. 


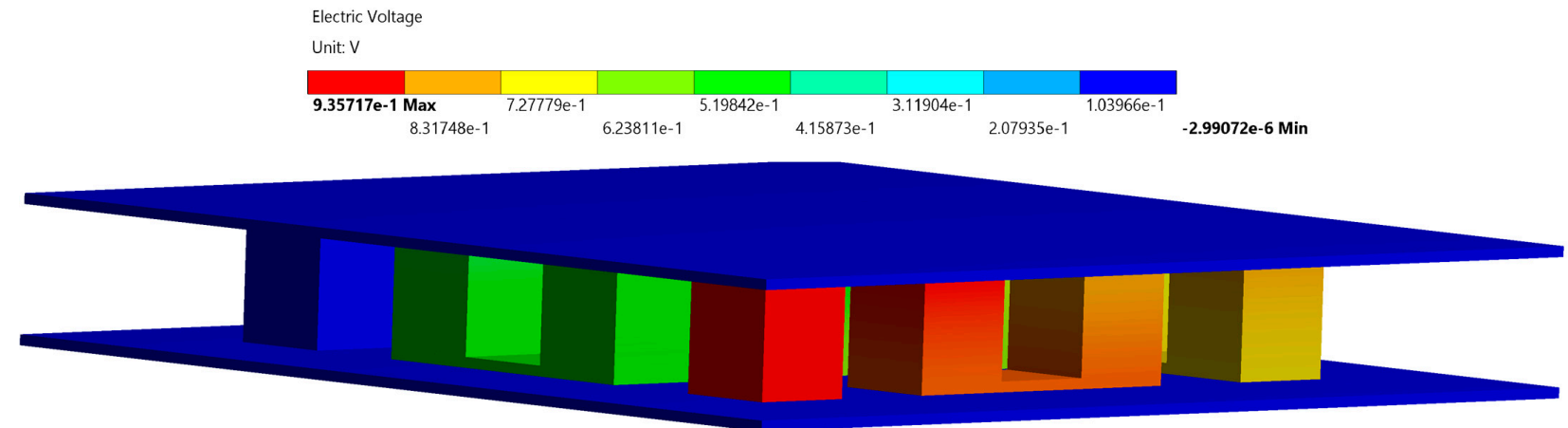

Figure 11. Electric potential for a TEG cooled with distilled water, using thermoelement measurements of the equivalent geometry B.

In comparison with basic fluids, using GNAN with a larger mass fraction, $\mathrm{h}$ and the heat transfer increases.

The equivalent rectangular geometry $B$ has the greatest efficiency between the rectangular models A, B, and C. We will use it as the optimum rectangular geometry for different convective coefficients, using different mass fractions of refrigerants, as shown in Figure 12. It is shown that the heat $Q_{h}$ tends to increase with increasing flow. If the Reynolds number exceeds 250, the improvement is slow

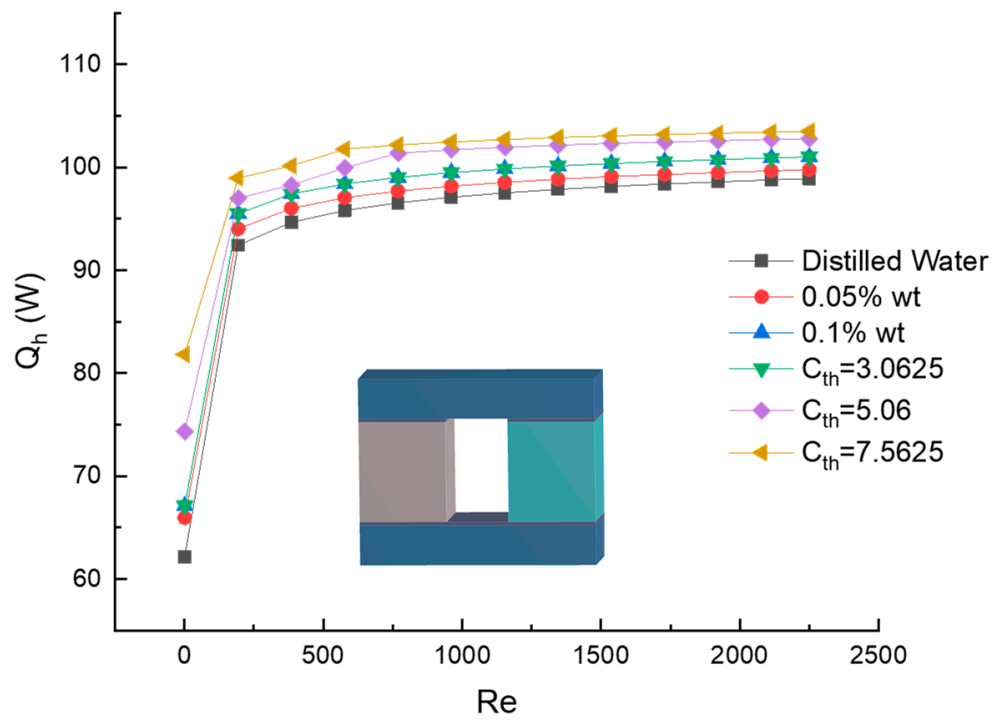

Figure 12. Heat absorbed vs. Reynolds number of equivalent model B with distilled water, $0.5 \% \mathrm{wt}$ and $0.1 \%$ wt at a thermal concentration ratio of 3.0625 .

Based on the method of [31], GNPS are loaded in distilled water with different weight dispersions: $0.025 \%, 0.05 \%, 0.075 \%$, and $0.1 \%$ wt. Nanofluid dispersed in graphene was used as the refrigerant on the cold side of the Solar-TEG.

The maximum heat with $0.1 \% \mathrm{wt}$ is $101.01 \mathrm{~W}$, while using distilled water it is $98.89 \mathrm{~W}$. This also shows the heat as a function of Reynolds number but with different concentration ratios, $C_{\text {th }}$. In that case, the maximum heat at a $C_{\text {th }}$ of 7.5625 and 3.0625 is $102.49 \mathrm{~W}$ and $94.37 \mathrm{~W}$, respectively. Those results are with $0.1 \% \mathrm{wt}$.

The heat absorbed on the Solar-TEG's hot side is converted partly into electrical energy and partially is transferred to the heat dissipator to the cold side. Increasing the flow to improve the heat transfer of the refrigerant will increase the heat gain on the high-temperature side by the same amount. Figure 13 shows the dependence of the output power on the refrigerant flow rate under different conditions on the cold side. The resulting power output is displayed as a function of Reynolds number and concentration 
ratio, respectively. If the resistance of the output circle is stable, then the output power is secondly dependent on the voltage.

a)

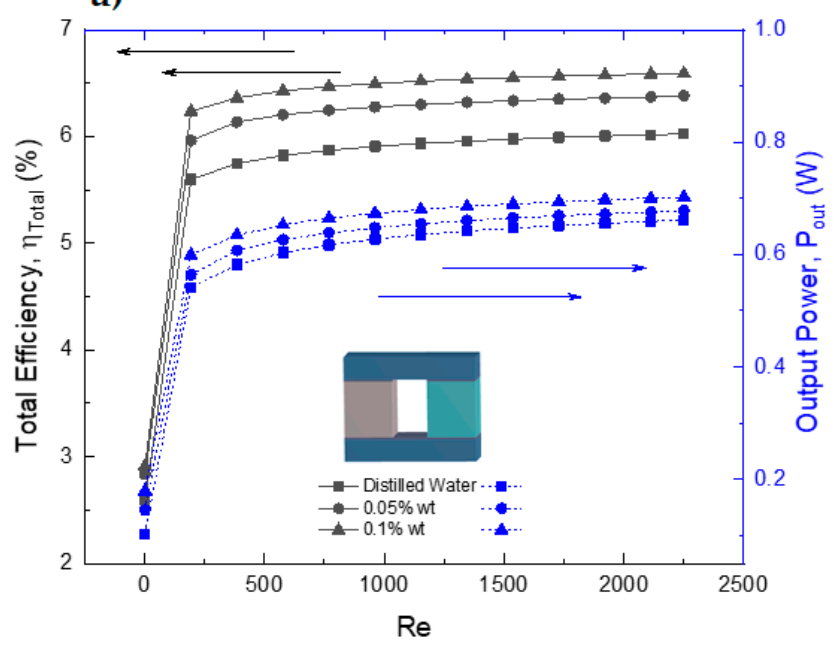

b)

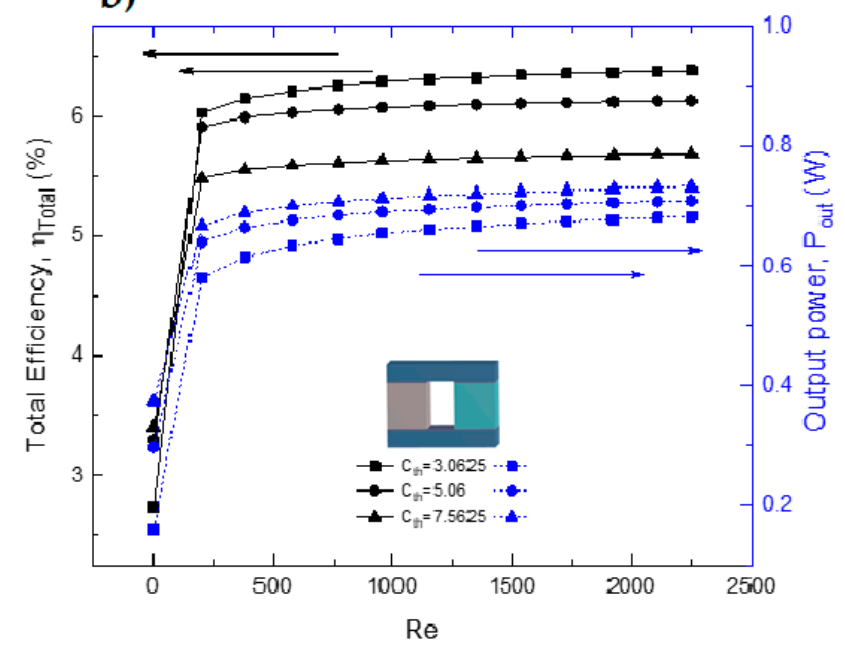

Figure 13. (a) Efficiency and $P_{\text {out }}$ vs. Reynolds number of equivalent model $B$ with distilled water and graphene nanoplatelet nanofluids at different concentrations. (b) Efficiency and $\mathrm{P}_{\text {out }}$ vs. Reynolds number of equivalent model B with different concentrations ratios at $0.1 \%$ wt of GNAN.

Using conventional refrigerants as air, the efficiency of rectangular model B is $5.65 \%$. Using GNANs at $0.1 \% \mathrm{wt}$, the maximum efficiency of rectangular model B is $6.59 \%$. In Figure 13, in comparison with Figure 8, the efficiency improvement ratio is $7 \%, 10 \%, 12 \%$, and $15 \%$, for $0-0.025 \%, 0.025-0.05 \%, 0.05-0.075 \%$, and $0.075-0.1 \%$ wt of GNAN, respectively. The Reynolds number does not have much effect on the efficiency gain. Figure 13 shows the efficiency but with different thermal concentration ratios using GNANs at $0.1 \%$ wt. With a $\mathrm{C}_{\mathrm{th}}$ of 3.0625 , the maximum efficiency is $6.38 \%$. The improvement is $12 \%$ in comparison with the results shown in Figure 8.

The influence of the nano-liquid refrigerant on the conversion of thermal energy to electrical energy in the TEG system is in Figure 13a, which also shows the dependence of the output power on the refrigerant flow rate under different cold conditions.

Figure $13 \mathrm{~b}$ shows results with different concentration ratios. The maximum power it reaches is 0.731 Watts and 0.702 Watts, respectively. The behavior of both graphs is similar. When the Reynolds number rises from 0 to 193, there is a significant increase in the output power. From 193-2250, the increase of power is slower and almost imperceptible.

\subsubsection{Trapezoidal Models}

To observe the performance in trapezoidal geometries, we use GNAN in both models to perform corresponding simulations.

Figure 14 shown the electrical potential for the trapezoidal model A. While the heat transfer is higher, the coolant leads to a better voltage in the Solar-TEG. The captured electrical $\mathrm{P}_{\text {out }}$ is about $0.87622 \mathrm{~V}$ for a Solar-TEG with $0.1 \% \mathrm{wt}$ GNAN as the coolant. 

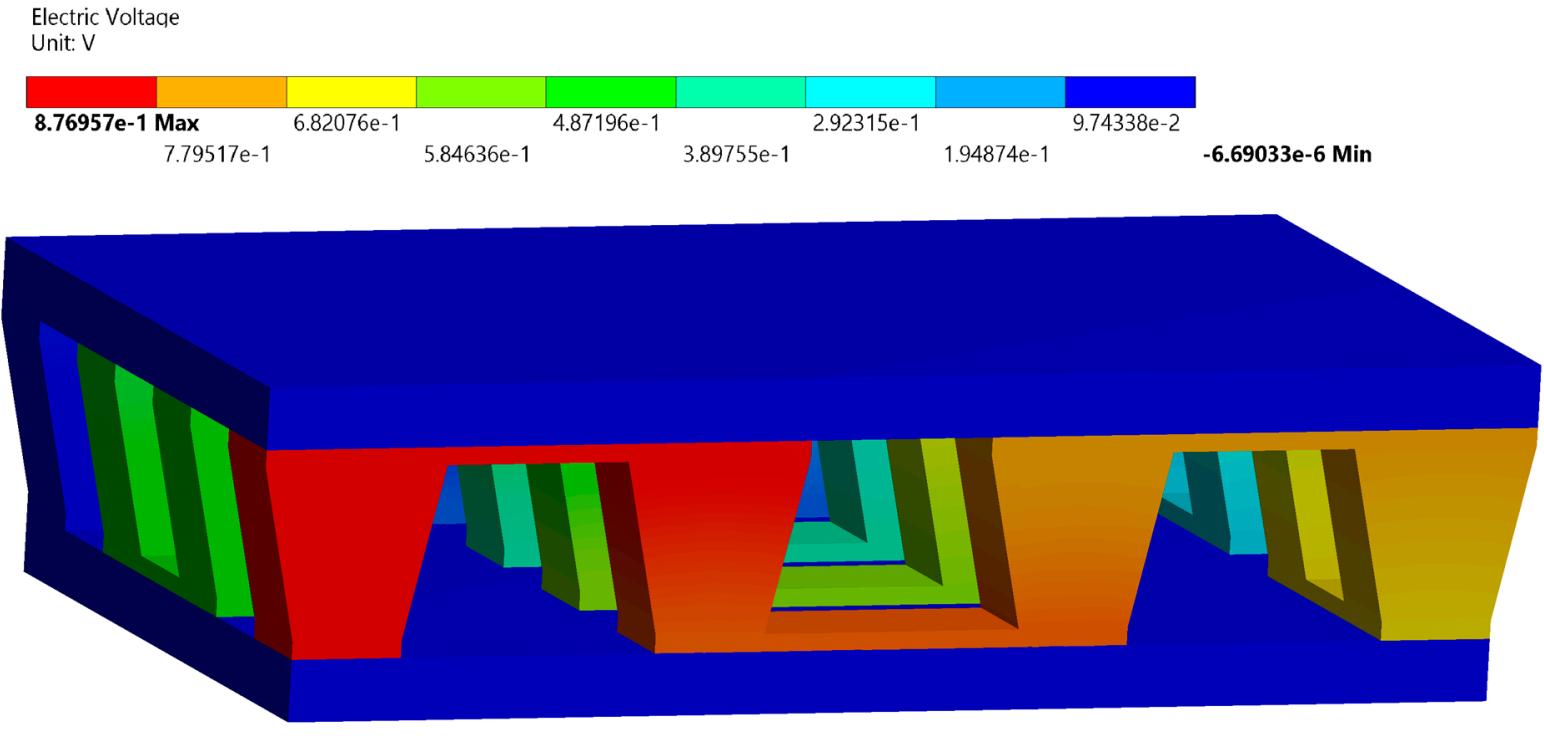

Figure 14. Electrical potential for a TEG cooled with distilled water, using trapezoidal thermoelements.

For the trapezoidal model B, we compare the efficiency at different concentrations of GNAN, as mentioned above. Raising the flow, the heat transfer of the refrigerant improves, and the heat absorption increases. The efficiency increase is shown in Figure 15. For distilled water, $0.05 \%$, and $0.1 \% \mathrm{wt}$, the maximum efficiency is $7.09 \%, 7.27 \%$, and $7.31 \%$ respectively.

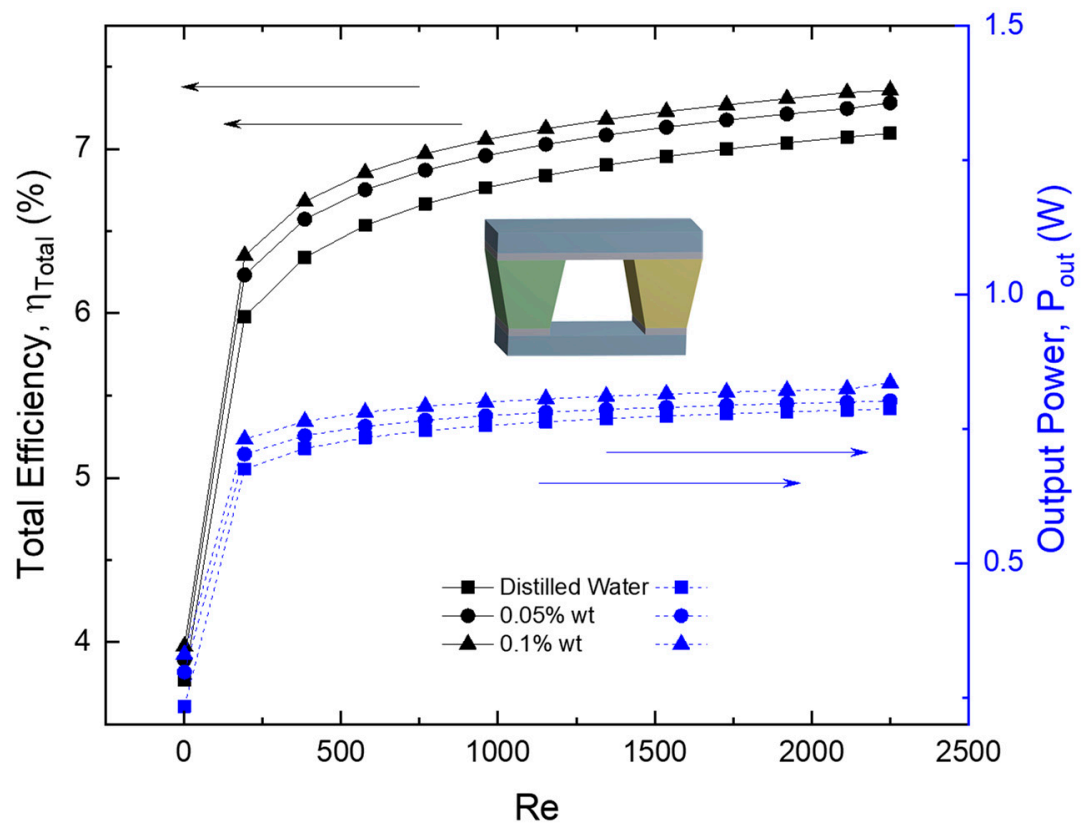

Figure 15. Total efficiency and $P_{\text {out }}$ vs. Reynolds number of trapezoidal model B and rectangular model B with concentration $0.1 \%$ wt and two different thermal concentration ratios.

The maximum output power is $0.786 \mathrm{~W}, 0.80 \mathrm{~W}$, and $0.835 \mathrm{~W}$ for distilled water, $0.05 \%$ $w t$, and $0.1 \% w t$, respectively

Figure 16 shown a comparison between rectangular and trapezoidal models of efficiency in function of Reynolds number at $0.1 \% \mathrm{wt}$ and with their respective smallest $\mathrm{C}_{\text {th }}$. For both models, the efficiency is better than the efficiency with their $C_{\text {th }}$. For the rectangular model, the maximum efficiency is $6.37 \%$ and $6.59 \%$ at a $C_{\text {th }}=3.0625$ and $0.1 \%$ wt, respectively. The maximum efficiency for the trapezoidal model is $7.14 \%$ and $7.35 \%$ at 
a $C_{t h}=11.11$ and $0.1 \% \mathrm{wt}$, respectively. This shows that using nanofluids generates better performance in a Solar-TEG.

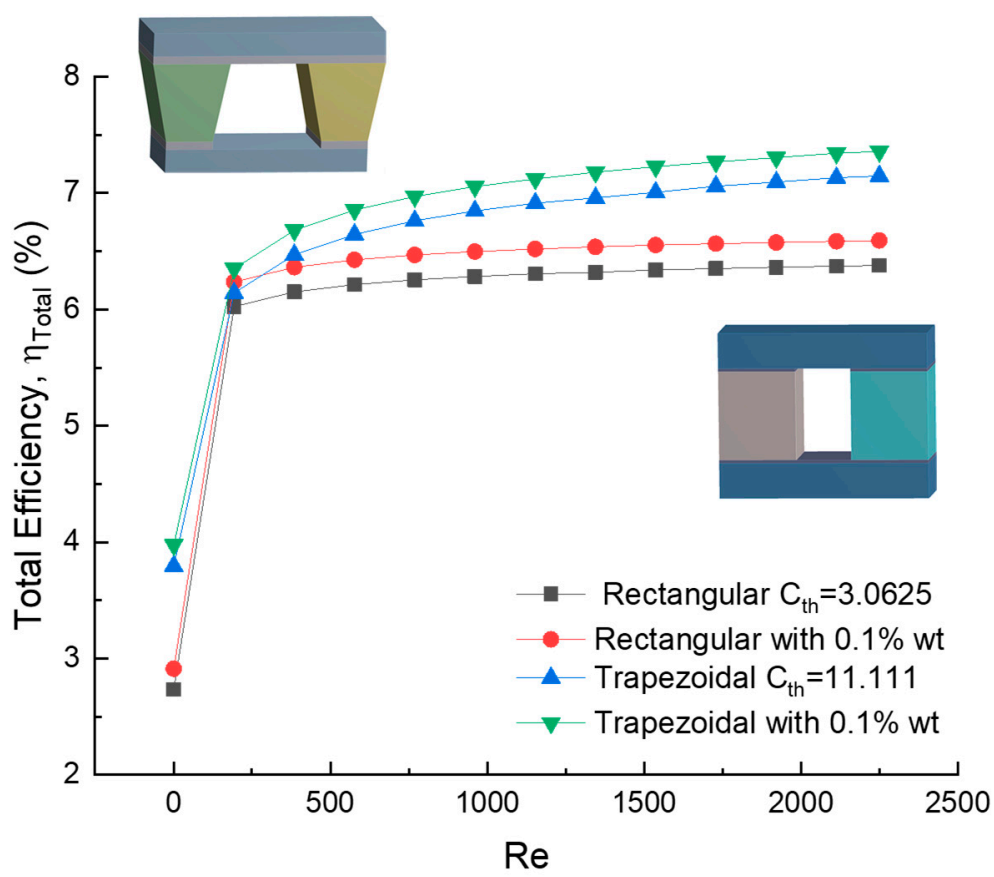

Figure 16. Total efficiency vs. Reynolds number of trapezoidal model B and rectangular model B with concentration $0.1 \%$ wt and two different thermal concentration ratios.

Table 7 shows our maximum efficiency results when Solar-TEG is cooled with air and with GNAN, compared to the results obtained from the study by Wei-Hsin Chen et al. [8] and Lamba [18]. A significant improvement in efficiency is perceived when GNAN is used as a refrigerant.

Table 7. Comparison of our results with results of other studies.

\begin{tabular}{cccccc}
\hline & $\begin{array}{c}\text { GNAN } \\
\text { Trapezoidal } \\
\text { Model }\end{array}$ & $\begin{array}{c}\text { GNAN } \\
\text { Rectangular } \\
\text { Model }\end{array}$ & Air & $\begin{array}{c}\text { Wei-Hsin } \\
\text { Chen [8] }\end{array}$ & Lamba [18] \\
\hline $\begin{array}{c}\text { Maximmum } \\
\text { Efficiency }\end{array}$ & $7.31 \%$ & $6.37 \%$ & $5.65 \%$ & $4.3 \%$ & $6.33 \%$ \\
\hline
\end{tabular}

\section{Conclusions}

The performance of a thermally concentrated Solar-TEG was studied, employing FEM and performing simulations in an ANSYS workbench. The properties of semiconductors are temperature-dependent, based on commercial materials. Therefore, equivalent models were developed to facilitate simulation. Three-dimensional steady-state geometries were designed to simulate the heat transfer behavior and efficiency of Solar-TEG. To achieve better cooling, GNAN was used.

Five different Solar-TEG geometries (three rectangular and two trapezoidal models) were evaluated and compared. $P_{\text {out }}$ of the Solar-TEG increased as the surface area increased with the increase in the heat concentration coefficient. Geometry B offered the best performance, and the largest was $5.65 \%$, with a panel area of $110 \times 110 \mathrm{~mm}^{2}$. If the length of the element is set, reducing the cross-section of the thermoelectric element is the best way to improve efficiency. If forced convection occurs below $\mathrm{h}=500 \mathrm{~W} / \mathrm{m}^{2} \mathrm{~K}$, the cooling conditions have little effect on solar TEG behavior.

When the value of the convection coefficient was very low $\left(10 \mathrm{~W} / \mathrm{m}^{2} \mathrm{~K}\right)$, the efficiency dropped significantly due to the low heat transfer generated with this coefficient. Our 
results of Solar-TEG systems with nanofluids have shown a significantly improvement in TEG efficiency. A clear increase in $\mathrm{P}_{\text {out }}$ and the voltage of Solar-TEG using GNAN refrigerants were seen with the addition of $0.025,0.05,0.075$, and $0.1 \%$ wt. Conversion efficiency was increased by $7 \%, 10 \%, 12 \%$, and $15 \%$ for $0.025,0.05,0.075$, and $0.1 \%$ wt GNAN, respectively.

Author Contributions: Conceptualization, M.A.O.-R.; Formal analysis, M.A.O.-R.; Investigation, M.A.O.-R.; Methodology, C.F.R.-C.; Project administration, J.V.M.-M.; Resources, J.V.M.-M.; Validation, J.V.M.-M.; Visualization, C.F.R.-C.; Writing—original draft, C.F.R.-C.; Writing—review \& editing, M.A.O.-R. All authors have read and agreed to the published version of the manuscript.

Funding: The work was supported by the National Polytechnic Institute (no. 20210403) and the National Council for Science and Technology (CVU 826630).

Institutional Review Board Statement: Not applicable.

Informed Consent Statement: Informed consent was obtained from all subjects involved in the study.

Data Availability Statement: Data available on request due to restrictions, e.g., privacy or ethics. The data presented in this study are available on request from the corresponding author. However, the data are not publicly available because our research group is still in further research in this area.

Conflicts of Interest: The authors declare no conflict of interest.

\section{References}

1. Wang, X.-D.; Huang, Y.-X.; Cheng, C.-H.; Lin, D.; Kang, C.-H. A three-dimensional numerical modeling of thermoelectric device with consideration of coupling of temperature field and electric potential field. Energy 2012, 47, 488-497. [CrossRef]

2. Gou, X.; Yang, S.; Xiao, H.; Ou, Q. A dynamic model for thermoelectric generator applied in waste heat recovery. Energy 2013, 52, 201-209. [CrossRef]

3. Kimmel, J. Thermoelectric Materials. Physics 1999, 152.

4. Ewert Michael, K. Terrestrial and Aerospace Solar Heat Pump Development: Past, present, and future. Sol. Eng. 1998, 375-382.

5. Chen, G.; Mu, Y.; Zhai, P.; Li, G.; Zhang, Q. An Investigation on the Coupled Thermal-Mechanical-Electrical Response of Automobile Thermoelectric Materials and Devices. J. Electron. Mater. 2013, 42, 1762-1770. [CrossRef]

6. Riffat, S.B.; Ma, X. Thermoelectrics: A review of present and potential applications. Appl. Therm. Eng. 2003, $23,913-935$. [CrossRef]

7. Rowe, D.M. Thermoelectric Handbook: Macro to Nano; CRC Press: Boca Raton, FL, USA, 2005.

8. Chen, W.-H.; Wang, C.-C.; Hung, C.-I.; Yang, C.-C.; Juang, R.-C. Modeling and simulation for the design of thermal-concentrated solar termoelectric generator. Energy 2014, 64, 287-297. [CrossRef]

9. Figueiredo, M.; Marseglia, G.; Moita, A.S.; Panão, M.R.O.; Ribeiro, A.P.C.; Medaglia, C.M.; Moreira, A.L.N. Thermofluid characterization of nanofluid spray cooling combining Phase Doppler Interferometry with high-speed visualization and timeresolved IR thermography. Energies 2020, 13, 5864. [CrossRef]

10. Sanches, M.; Marseglia, G.; Ribeiro, A.; Moreira, A.; Moita, A. Nanofluids Characterization for Spray Cooling Applications. Symmetry 2021, 13, 788. [CrossRef]

11. Sandhya, M.; Ramasamy, D.; Sudhakar, K.; Kadirgama, K.; Samykano, M.; Harun, W.; Najafi, G.; Mofijur, M.; Mazlan, M. A systematic review on graphene-based nanofluids application in renewable energy systems: Preparation, characterization, and thermophysical properties. Sustain. Energy Technol. Assess. 2021, 44, 101058. [CrossRef]

12. Rockendorf, G.; Sillmann, R.; Podlowski, L.; Litzenburger, B. PV-hybrid and thermoelectric collectors. Sol. Energy 1999, 67, $227-237$. [CrossRef]

13. Omer, S.A.; Infield, D.G. Design and thermal analysis of a two stage solar concentrator for combined heat and thermoelectric power generation. Energy Convers. Manag. 2000, 41, 737-756. [CrossRef]

14. Lenoir, B.; Dauscher, A.; Poinas, P.; Scherrer, H.; Vikhor, L. Electrical performance of skutterudites solar thermoelectric generators. Appl. Therm. Eng. 2003, 23, 1407-1415. [CrossRef]

15. Nuwayhid, R.Y.; Shihadeh, A.; Ghaddar, N. Development and testing of a domestic woodstove thermoelectric generator with natural convection cooling. Energy Convers. Manag. 2005, 46, 1631-1643. [CrossRef]

16. Kossyvakis, D.; Vossou, C.; Provatidis, C.; Hristoforou, E. Computational analysis and performance optimization of a solar thermoelectric generator. Renew. Energy 2015, 81, 150-161. [CrossRef]

17. Baranowski, L.L.; Snyder, J.; Toberer, E. Concentrated solar thermoelectric generators. Energy Environ. Sci. 2012, 5, 9055-9067. [CrossRef]

18. Lamba, R.; Kashik, S.C. Thermodynamic analysis of thermoelectric generator including the influence of Thompson effect and leg geometry configuration. Energy Convers. Manag. 2017, 144, 388-398. [CrossRef] 
19. Kraemer, D.; Poudel, B.; Feng, H.-P.; Caylor, J.C.; Yu, B.; Yan, X.; Ma, Y.; Wang, X.; Wang, D.; Muto, A.; et al. High-performance flat-panel solar thermoelectric generators with high thermal concentration. Nat. Mater. 2011, 10, 532-538. [CrossRef] [PubMed]

20. Schmitz, A.; Stiewe, C.; Zabrocki, K.; De Boor, J.; Mull, K.; Müller, E. Current assisted sintering of PbTe-Effects on thermoelectric and mechanical properties. Mater. Res. Bull. 2017, 86, 159-166. [CrossRef]

21. Zhou, M.; He, Y.; Chen, Y. A heat transfer numerical model for thermoelectric generator with cylindrical shell and straight fins under steady-state conditions. Appl. Therm. Eng. 2014, 68, 80-91. [CrossRef]

22. Huang, Y.-X.; Wang, X.-D.; Cheng, C.-H.; Lin, D. Geometry optimization of thermoelectric coolers using simplified conjugategradient method. Energy 2013, 59, 689-697. [CrossRef]

23. Bahiraei, M.; Hangi, M. Investigation the efficacy of magnetic nanofluid as a coolant in a double-pipe heat exchanger in the presence of the magnetic field. Energy Convers. Manag. 2013, 76, 1125-1133. [CrossRef]

24. Faizal, M.; Saidur, R.; Mekhilef, S.; Alim, M. Energy, economic and environmental analysis of metal oxides nanofluid for flat-plate solar collector. Energy Convers. Manag. 2013, 76, 162-168. [CrossRef]

25. Hajian, R.; Layeghi, M.; Sani, K.A. Experimental study of nanofluid effects on the thermal performance with response time of heat pipe. Energy Convers. Manag. 2012, 56, 63-68. [CrossRef]

26. Koo, J.; Kleinstreuer, C. A new thermal conductivity model for nanofluids. J. Nanopart. Res. 2004, 6, 577-588. [CrossRef]

27. Peyghambarzadeh, S.; Hashemabadi, S.; Naraki, M.; Vermahmoudi, Y. Experimental study of overall heat transfer coefficient in the application of dilute nanofluids in the car radiator. Appl. Therm. Eng. 2013, 52, 8-16. [CrossRef]

28. Naraki, M.; Peyghambarzadeh, S.; Hashemabadi, S.; Vermahmoudi, Y. Parametric study of overall heat transfer coefficient of $\mathrm{CuO} /$ water nanofluids in a car radiator. Int. J. Therm. Sci. 2013, 66, 82-90. [CrossRef]

29. Vermahmoudi, Y.; Peyghambarzadeh, S.M.; Hashemabadi, S.H.; Naraki, M. Experimental investigation on heat transfer performance of Fe2O3/water nanofluid in an air-finned heat exchanger. Eur. J. Mech. B/Fluids 2014, 44, 32-41. [CrossRef]

30. Cuce, E.; Guclu, T.; Cuce, P.M. Improving thermal performance of thermoelectric coolers (TECs) through a nanofluid driven water to air heat exchanger design: An experimental research. Energy Convers. Manag. 2020, 214, 112893. [CrossRef]

31. Xing, J.-J.; Wu, Z.-H.; Xie, H.-Q.; Wang, Y.-Y.; Li, Y.-H.; Mao, J.-H. Performance of thermoelectric generator with graphene nanofluid cooling. Chin. Phys. B 2017, 26, 104401. [CrossRef]

32. Mohammadian, S.K.; Zhang, Y. Analysis of nanofluid effects on thermoelectric cooling by micro-pin-fin heat exchangers. Appl. Therm. Eng. 2014, 70, 282-290. [CrossRef]

33. Selimefendigil, F.; Öztop, H. Identification of pulsating flow effects with CNT nanoparticles on the performance enhancements of thermoelectric generator (TEG) module in renewable energy applications. Renew. Energy 2020, 162, 1076-1086. [CrossRef]

34. Wiriyasart, S.; Suksusron, P.; Hommalee, C.; Siricharoenpanich, A.; Naphon, P. Heat transfer enhancement of thermoelectric cooling module with nanofluid and ferrofluid as base fluids. Case Stud. Therm. Eng. 2021, 24, 100877. [CrossRef] 